\title{
Prognostic and clinicopathological importance of microRNA-140 expression in cancer patients: a meta-analysis
}

\author{
Mengxia Zheng ${ }^{1 \dagger}$, Jingting Liu ${ }^{2 \dagger}$, Chunyan Meng ${ }^{1}$, Kaifeng Tang ${ }^{1}$ and Jianhua Liao ${ }^{1 *}$ (D)
}

\begin{abstract}
Background: MicroRNA-140 (miR-140) is one of the most widely investigated miRNAs in cell carcinogenesis and cancer development. Despite present proposals of employing miR-140 as a candidate biomarker for cancer prognosis, its effectiveness in predicting patient survival and clinicopathological outcome is still under debate.

Methods: A systematic search for English literature using online databases was performed with pre-established criteria. Odds ratios (ORs) or hazard ratios (HRs) with 95\% confidence intervals (Cls) were collected to delineate the correlation between miR-140 levels and cancer patient prognosis.

Results: For this meta-analysis, we selected 12 papers for analysis, involving 1386 participants. Based on our analysis, high levels of miR-140 were strongly correlated with enhanced patient overall survival (OS) (HR $=0.728$, $95 \% \mathrm{Cl}=0.601-0.882, P=0.001)$. In addition, we also observed that elevated miR-140 levels significantly led to better OS in patients with cancers in different parts of the body like digestive system $(\mathrm{HR}=0.675,95 \% \mathrm{Cl}=0.538$ $0.848, P=0.001)$, digestive tract $(H R=0.709,95 \% \mathrm{Cl}=0.565-0.889, P=0.003)$, and head and neck $(\mathrm{HR}=0.603,95 \%$ $\mathrm{Cl}=0.456-0.797, P<0.001)$. Additionally, we verified that the low miR-140 levels was related to advanced TNM stage $(\mathrm{OR}=0.420,95 \% \mathrm{Cl}=0.299-0.590, P<0.001)$, worse histologic grade $(\mathrm{OR}=0.410,95 \% \mathrm{Cl}=0.261-0.643, P<$ $0.001)$, and positive lymph node metastasis status $(\mathrm{OR}=0.341,95 \% \mathrm{Cl}=0.144-0.807, P=0.014)$.

Conclusions: Taken together, our results suggest that elevated miR-140 levels can be employed as a favorable biomarker for cancer patient prognosis. This information can greatly benefit in the formation of an individualized therapeutic plan for the treatment of cancer patients.
\end{abstract}

Keywords: Cancer, MicroRNA-140, Meta-analysis, Prognosis, Biomarker

\section{Background}

MicroRNA-140 (miR-140) is one of the most widely investigated miRNAs in cell carcinogenesis and cancer development. Despite present proposals of employing miR140 as a candidate biomarker for cancer prognosis, its effectiveness in predicting patient survival and

\footnotetext{
* Correspondence: ljhsywzh@163.com

${ }^{+}$Mengxia Zheng and Jingting Liu contributed equally to this work. 'Department of General Surgery, Affiliated Zhejiang Hospital, Zhejiang University School of Medicine, 12 Lingyin Road, Zhejiang 310013, Hangzhou, China

Full list of author information is available at the end of the article
}

clinicopathological outcome is still under debate. Here, we explored the association between miR-140 levels and clinicopathological features and patient prognosis in cancer by conducting an exhaustive review of relevant literature, with a goal to clarify the role of miR-140 in cancer.

\section{Introduction}

Cancer is the most common noncommunicable disease and is expected to continue to rank as the leading cause of death worldwide [1]. Despite the advances in cancer

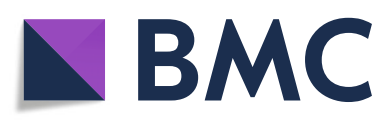

(c) The Author(s). 2021 Open Access This article is licensed under a Creative Commons Attribution 4.0 International License, which permits use, sharing, adaptation, distribution and reproduction in any medium or format, as long as you give appropriate credit to the original author(s) and the source, provide a link to the Creative Commons licence, and indicate if changes were made. The images or other third party material in this article are included in the article's Creative Commons licence, unless indicated otherwise in a credit line to the material. If material is not included in the article's Creative Commons licence and your intended use is not permitted by statutory regulation or exceeds the permitted use, you will need to obtain permission directly from the copyright holder. To view a copy of this licence, visit http://creativecommons.org/licenses/by/4.0/ The Creative Commons Public Domain Dedication waiver (http://creativecommons.org/publicdomain/zero/1.0/) applies to the data made available in this article, unless otherwise stated in a credit line to the data. 
treatment worldwide that have occurred in recent years and the improvements made in cancer prevention, diagnosis, surgery, and adjuvant therapy, cancer incidence and mortality are inexorably increasing worldwide. In addition to taking effective measures to improve the effects of aging and growth of the population and unequal socioeconomic development, researchers have carried out a large number of small and more in-depth studies to explore and mitigate the cancer burden [2]. To date, cancer-related lncRNAs, miRNAs, RNAs, and proteins have been continuously discovered to be related to prognosis after surgery [3-5]. However, paradoxical results have always appeared in previous studies; therefore, we conducted this analysis to find a stable prognostic marker that could potentially reduce the future cancer burden.

MicroRNAs (miRNAs), a class of conserved noncoding RNA 18-25 nucleotides in length, have attracted extensive attention in recent years and function in cancer pathogenesis through the cleavage or translational repression of targeted mRNAs [6]. As a small part of the entire human genome, miRNAs modulate levels of a considerable number of human genes, especially cancerassociated genes [7]. Meanwhile, a large quantity of miRNAs originates from genomic regions involved in cancer regulation. Moreover, miRNAs exert their biological role via regulation of cell proliferation, apoptosis, differentiation, and migration [8]. Indeed, emerging evidences suggest a strong relationship between aberrant miRNAs levels and various cancers. Among these miRNAs, miR140 is one of the most widely investigated miRNAs in cell carcinogenesis and cancer development. It is well known that miR-140 is encoded within intron 16 of Wwp2 on the human chromosome 16 region and has a dual role in cancer progression [9]. On the one hand, miR-140 plays a tumor suppressive role in cancer. As revealed in published studies, suppression of cancer stem cell survival and invasive potential, cell cycle arrest, regulation of DNA synthesis and caspase 3/7 activity, control of NF- $\mathrm{kB}$ activity, and regulation of oncogenic protein expression correlate with miR-140 expression and miR-140 suppresses tumorigenesis by targeting various genes [10-12]. Alternately, Güllü et al. reported remarkably high expression of miR-140 in cancer tissues, which accelerates tumor progression [13]. Moreover, Meng et al. proposed that miR-140 modulates osteosarcomic chemoresistance via HMGN5 and autophagy regulation [14]. In addition, miR-140 is related to decreased levels of IGFBP- 5 and involved in tamoxifen resistance in breast cancer [15]. Likewise, the clinical results of miR-140-related studies revealed similar findings as those of mechanistic studies. Therefore, given the importance of miR-140 in cancer, the exact function of miR-140 in different cancers should be further verified. However, thus far, there is no comprehensive analysis of miR-140 expression and its function in cancer patients.

Here, we explored the association between miR-140 levels and clinicopathological features (CPF) and patient prognosis in cancer by conducting an exhaustive review of relevant literature, with a goal to clarify the role of miR-140 in cancer.

\section{Materials and methods}

\section{Search strategy and study selection}

We carefully performed an exhaustive search for English publications using online databases, like PubMed, Embase, and the Cochrane Library from the inception of the databases to May 10, 2021. We employed keywords like "microRNA-140 OR miR-140" AND "cancer or tumor or malignancy or neoplasm or carcinoma" AND "prognosis or prognostic or survival or outcome." Additionally, to conduct a thorough search of all relevant papers, we also scanned the references of all eligible papers to find publications that were missed in the previous search. Two authors separately reviewed all articles. A third author was available for discussion and resolution of any conflicts in data and conclusion. Details of the protocol for this systematic review were registered on INPLASY (INPLASY202180037) and are available in full on the inplasy.com (https://doi.org/10.37766/ inplasy2021.8.0037). This meta-analysis followed the strict guidelines of the reporting checklist that was included in the preferred reporting items for systematic reviews and meta-analyses statement [16].

\section{Study eligibility and ineligibility criteria}

The following articles were included in our analysis: (1) all adult participants received a pathological diagnosis of cancer and received reasonable and effective therapeutic measures; (2) examination of miR-140 levels in cancerous tissues or blood; (3) all participants were separated into cohorts, based on their miR-140 levels, and survival analysis was completed on both cohorts; (4) sufficient data were provided to measure the hazard ratio (HR) and $95 \%$ confidence intervals (CI); and (5) studies involved more than 50 enrolled patients. Any articles that failed to comply with the above criteria were eliminated from our analysis. In addition, case reports, reviews, conference abstracts, letters, and animal trials were also excluded.

\section{Data accumulation and quality assessment}

All data was separately compiled by two scientists. Relevant data included authors, publication year, research location, recruitment duration, population size, cancer type, detection procedure, detected sample, threshold, analysis type, HR prediction, and CPF. Study quality was 
assessed according to the Newcastle-Ottawa Quality Assessment Scale (NOS) [17].

\section{Statistical analysis}

STATA 14.0 software (STATA Corporation, College Station, Texas, USA) was employed for all analyses. HRs and their subsequent 95\% CIs were pooled to examine the association between miR-140 levels and the overall survival (OS) of cancer patients, and HRs from multivariate analyses in each study were preferentially included in the analysis. The relationship between miR140 levels and CPF was examined by pooling the odds ratios (ORs) and their subsequent 95\% CIs. The chisquare test and $I^{2}$ statistic were employed to test heterogeneity. A fixed-effects model was used if the $P$ value exceeded 0.05 and/or the $I^{2}$ was less than $50 \%$. Otherwise, the random-effects model was employed. Subgroup analyses were used to establish the relationship between miR-140 levels and cancer patient prognosis and to explore possible factors contributing to heterogeneity. Meanwhile, meta-regression was employed to further explore the heterogeneity among studies. Sensitivity analysis was carried out to confirm the stability of the accumulated consequences of miR-140 levels, in terms of the overall OS rate HR prediction. Begg's and Egger's tests analyzed publication bias. Two-sided $P<0.05$ was significance threshold.

\section{Results}

\section{Literature search and research characteristics}

The article eligibility process is summarized in Fig. 1 . According to the prespecified keywords, we found 345 relevant articles in the initial search. After carefully reviewing the titles and abstracts, 302 of them were deemed ineligible since they were review articles, letters, basic research, etc. Then, we screened the remaining 43 studies for eligibility. Thirty-one of them were further excluded (TCGA studies $[n=17]$, cancer-specific



Fig. 1 A summary of study eligibility and ineligibility process 
survival and relapse-free survival and disease-free survival articles $[n=7]$, absence of survival data or small sample population $[n=6]$, pediatric cancer research $[n$ = 1]). Finally, 12 articles covering 1386 patients from 2013 to 2020 were eligible for the meta-analysis. All patients were located in China and were diagnosed with different forms of cancer, including hepatocellular [18], gastric [19, 20], colorectal [21], nasopharyngeal [22-24], breast [25], cutaneous [26], esophageal squamous cell [27], thyroid [28], and renal cell [29]. MiR-140 levels were examined via quantitative real-time polymerase chain reaction (qRT-PCR) in 11 studies. Only one study used in situ hybridization. In most of the studies, miR140 expression was measured in cancer tissues, whereas in three articles, it was measured in the serum. Six studies provided the median expression level of miR-140 as the cutoff value, and 6 studies used other optimal cutoff values. HRs were extracted from all of the included studies, of which 9 were postoperative and 3 were postcombined treatment. As listed in Table 1, the articles were of high quality, based on NOS assessment (quality score $\geq 6$ ). More detailed information is presented in Table 1.

\section{Significance of miR-140 expression in the prognosis of cancer patients}

As indicated in Table 2, we demonstrated that elevated miR-140 levels in cancer was significantly correlated with enhanced patient OS than low miR-140 expression $(\mathrm{HR}=0.728,95 \% \mathrm{CI}=0.601-0.882, P=0.001$, Fig. 2$)$. Combined analysis also revealed that upregulated miR140 levels were correlated with increased OS in both the postoperative $(\mathrm{HR}=0.734,95 \% \mathrm{CI}=0.594-0.907, P=$ $0.004)$ and nonpostoperative groups $(\mathrm{HR}=0.636,95 \%$ $\mathrm{CI}=0.474-0.854, P=0.003)$. Specifically, we revealed that high miR-140 levels markedly enhanced OS in patients with digestive system cancer $(\mathrm{HR}=0.675,95 \% \mathrm{CI}$ $=0.538-0.848, P=0.001)$, digestive tract cancer $(\mathrm{HR}=$ $0.709,95 \% \mathrm{CI}=0.565-0.889, P=0.003)$, and head and neck cancer $(\mathrm{HR}=0.603,95 \% \mathrm{CI}=0.456-0.797, P<$ 0.001 ). In addition, the pooled HR suggested a strong association between miR-140 levels and OS in the

Table 1 Main characteristics of studies included in meta-analysis

\begin{tabular}{|c|c|c|c|c|c|c|c|c|c|c|c|}
\hline Author & Year & $\begin{array}{l}\text { Study } \\
\text { region }\end{array}$ & $\begin{array}{l}\text { Recruitment } \\
\text { time }\end{array}$ & $\begin{array}{l}\text { Sample } \\
\text { size }\end{array}$ & $\begin{array}{l}\text { Cancer } \\
\text { type }\end{array}$ & $\begin{array}{l}\text { Detection } \\
\text { method }\end{array}$ & $\begin{array}{l}\text { Detected } \\
\text { sample }\end{array}$ & $\begin{array}{l}\text { Cutoff scores } \\
\text { (high/low) }\end{array}$ & Analysis method & $\begin{array}{l}\text { OS, HR } \\
\text { estimation }\end{array}$ & $\begin{array}{l}\text { Quality } \\
\text { score }\end{array}$ \\
\hline Hao Y & 2013 & China & 2004-2007 & 120 & $\mathrm{HCC}$ & qRT-PCR & Tissues & Median & $\begin{array}{l}\text { Univariate/ } \\
\text { multivariate } \\
\text { analysis }\end{array}$ & $\begin{array}{l}0.47(0.25- \\
0.9)\end{array}$ & 8 \\
\hline Fang $Z$ & 2017 & China & NS & 144 & GC & $\mathrm{ISH}$ & Tissue & Optimal cutoff & $\begin{array}{l}\text { Univariate/ } \\
\text { multivariate } \\
\text { analysis }\end{array}$ & $\begin{array}{l}0.505 \\
(0.319- \\
0.801)\end{array}$ & 7 \\
\hline Li J & 2017 & China & NS & 63 & $\mathrm{CRC}$ & qRT-PCR & Blood & Median & Univariate analysis & $\begin{array}{l}0.77(0.65- \\
0.92)\end{array}$ & 6 \\
\hline Cha Y & 2018 & China & 2011-2015 & 60 & $\mathrm{GC}$ & qRT-PCR & Tissue & Median & Univariate analysis & $\begin{array}{l}0.39(0.17- \\
0.93)\end{array}$ & 7 \\
\hline Zhou Y & 2019 & China & 2010-2012 & 73 & $\mathrm{BC}$ & qRT-PCR & Tissue & Median & Univariate analysis & $\begin{array}{l}0.79(0.65- \\
0.96)\end{array}$ & 7 \\
\hline $\begin{array}{l}\text { Zhang } \\
\mathrm{H}\end{array}$ & 2020 & China & 2014-2016 & 200 & NPC & qRT-PCR & Blood & Median & Univariate analysis & $\begin{array}{l}1.04(0.41- \\
2.62)\end{array}$ & 6 \\
\hline Zou X & 2020 & China & 2014-2016 & 208 & NPC & qRT-PCR & Blood & Median & Univariate analysis & $\begin{array}{l}0.85(0.37- \\
1.98)\end{array}$ & 6 \\
\hline $\mathrm{He} Y$ & 2020 & China & NS & 104 & CM & qRT-PCR & Tissue & Optimal cutoff & $\begin{array}{l}\text { Univariate/ } \\
\text { multivariate } \\
\text { analysis }\end{array}$ & $\begin{array}{l}0.8(0.39- \\
0.92)\end{array}$ & 7 \\
\hline Yang H & 2020 & China & 1998-2003 & 113 & ESCC & qRT-PCR & Tissues & Optimal cutoff & $\begin{array}{l}\text { Multivariate } \\
\text { analysis }\end{array}$ & $\begin{array}{l}0.84(0.67- \\
1.05)\end{array}$ & 8 \\
\hline Yu Q & 2020 & China & 2009-2013 & 122 & $\mathrm{TC}$ & qRT-PCR & Tissues & Optimal cutoff & $\begin{array}{l}\text { Multivariate } \\
\text { analysis }\end{array}$ & $\begin{array}{l}0.369 \\
(0.152- \\
0.898)\end{array}$ & 8 \\
\hline Wu Q & 2020 & China & 2013-2018 & 105 & NPC & qRT-PCR & Tissues & Optimal cutoff & Univariate analysis & $\begin{array}{l}0.57(0.41- \\
0.8)\end{array}$ & 7 \\
\hline $\begin{array}{l}\text { Huang } \\
\text { C }\end{array}$ & 2020 & China & NS & 74 & $\mathrm{RCC}$ & qRT-PCR & Tissues & Optimal cutoff & $\begin{array}{l}\text { Multivariate } \\
\text { analysis }\end{array}$ & $\begin{array}{l}1.16(1.01- \\
1.33)\end{array}$ & 7 \\
\hline
\end{tabular}

HCC hepatocellular carcinoma, GC gastric cancer, CRC colorectal cancer, BC breast cancer, NPC nasopharyngeal carcinoma, CM cutaneous melanoma, ESCC esophageal squamous cell carcinoma, TC thyroid cancer, $R C C$ renal cell carcinoma, $q R T-P C R$ quantitative real-time PCR, ISH in situ hybridization, NS data were not shown, OS overall survival, HR hazard ratio 
Table 2 Meta-analysis of miR-140 expression and prognosis in cancers

\begin{tabular}{|c|c|c|c|c|c|c|}
\hline Categories & Studies (patients) & HR $(95 \% \mathrm{Cl})$ & $I^{2}(\%)$ & $P_{\mathrm{h}}$ & $Z$ & $P$ \\
\hline OS & $12(1386)$ & $0.728(0.601-0.882)$ & 73.8 & $<0.001$ & 3.25 & 0.001 \\
\hline Postoperative OS & $9(873)$ & $0.734(0.594-0.907)$ & 77.6 & $<0.001$ & 2.86 & 0.004 \\
\hline Non-postoperative OS & $3(513)$ & $0.636(0.474-0.854)$ & 0.0 & 0.377 & 3.01 & 0.003 \\
\hline \multicolumn{7}{|l|}{ Cancer type } \\
\hline Digestive system cancer & $5(500)$ & $0.675(0.538-0.848)$ & 51.1 & 0.085 & 3.37 & 0.001 \\
\hline Digestive tract cancer & $4(380)$ & $0.709(0.565-0.889)$ & 51.4 & 0.104 & 2.97 & 0.003 \\
\hline Head and neck cancer & $4(635)$ & $0.603(0.456-0.797)$ & 7.8 & 0.354 & 3.55 & $<0.001$ \\
\hline \multicolumn{7}{|l|}{ Analysis method } \\
\hline Multivariate analysis & $6(677)$ & $0.716(0.518-0.990)$ & 80.8 & $<0.001$ & 2.02 & 0.043 \\
\hline Univariate analysis & $9(1077)$ & $0.727(0.652-0.809)$ & 16.9 & 0.292 & 5.81 & $<0.001$ \\
\hline \multicolumn{7}{|l|}{ Publication date } \\
\hline$<5$ years & $9(1059)$ & $0.773(0.615-0.973)$ & 73.5 & $<0.001$ & 2.19 & 0.028 \\
\hline$\geq 5$ years & $3(327)$ & $0.618(0.427-0.876)$ & 55.9 & 0.104 & 2.71 & 0.007 \\
\hline \multicolumn{7}{|l|}{ Size } \\
\hline$<100$ & $4(270)$ & $0.832(0.623-1.112)$ & 85.8 & $<0.001$ & 1.24 & 0.215 \\
\hline$>100$ & $8(1116)$ & $0.699(0.602-0.811)$ & 34.4 & 0.153 & 4.73 & $<0.001$ \\
\hline \multicolumn{7}{|l|}{ Cutoff value } \\
\hline Median & $6(724)$ & $0.759(0.671-0.858)$ & 4.1 & 0.391 & 4.39 & $<0.001$ \\
\hline Optimal cutoff & $6(662)$ & $0.721(0.525-0.989)$ & 83.5 & $<0.001$ & 2.03 & 0.043 \\
\hline \multicolumn{7}{|l|}{ Detected sample } \\
\hline Tissue & $9(915)$ & $0.688(0.539-0.880)$ & 80.0 & $<0.001$ & 2.98 & 0.003 \\
\hline Blood & $3(471)$ & $0.781(0.660-0.923)$ & 0.0 & 0.806 & 2.90 & 0.004 \\
\hline
\end{tabular}

OS overall survival, $H R$ hazard ratio, $C l$ confidence interval, $P_{\mathrm{h}} P$ value for heterogeneity based on $Q$ test, $P P$ value for statistical significance based on $Z$ test

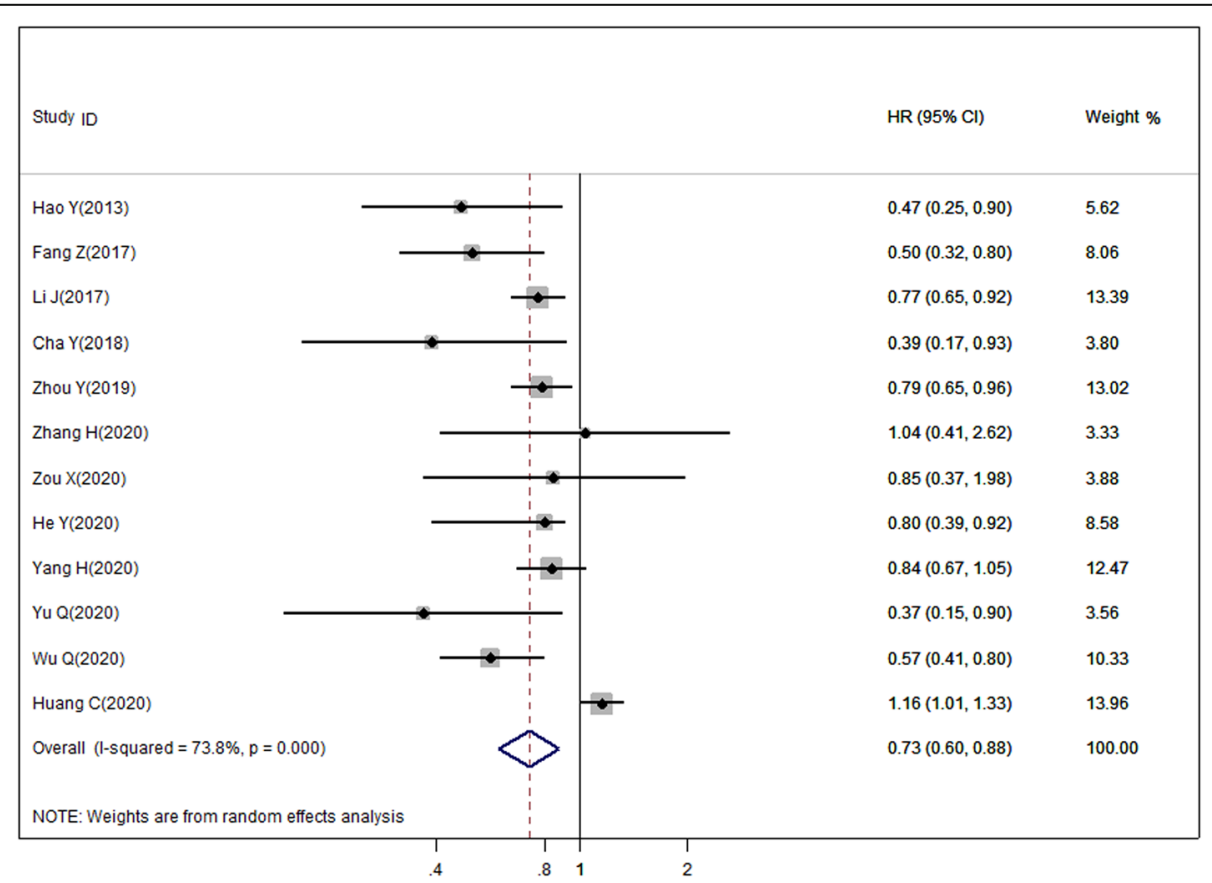

Fig. 2 Forest plot illustrating relationship between miR-140 levels and overall survival (OS) rate of cancer patients 
univariate $(\mathrm{HR}=0.727,95 \% \mathrm{CI}=0.652-0.809, P<0.001)$ and multivariate $(\mathrm{HR}=0.716,95 \% \mathrm{CI}=0.518-0.990, P=$ 0.043 ) subgroup, as well as in the tissue miR-140 ( $\mathrm{HR}=$ $0.688,95 \% \mathrm{CI}=0.539-0.880, P=0.003)$ and blood miR$140(\mathrm{HR}=0.781,95 \% \mathrm{CI}=0.660-0.923, P=0.004)$ subgroups. In the analysis stratified by cutoff value, we found that high miR-140 expression was still a predictor of OS in the median level $(\mathrm{HR}=0.759,95 \% \mathrm{CI}=0.671$ $0.858, P<0.001)$ and optimal cutoff value $(\mathrm{HR}=0.721$, $95 \%$ CI $=0.525-0.989, P=0.043)$ subgroups. Furthermore, this correlation was confirmed in the subgroup analysis based on publication date $(<5$ years, $\mathrm{HR}=$ $0.773,95 \% \mathrm{CI}=0.615-0.973, P=0.028 ; \geq 5$ years, $\mathrm{HR}=$ $0.618,95 \% \mathrm{CI}=0.427-0.876, P=0.007$, respectively). Moreover, a marked difference was also observed involving $>100$ patients $(\mathrm{HR}=0.699,95 \% \mathrm{CI}=0.602-0.811, P$ $<0.001)$ but not in studies with smaller sizes $(\mathrm{HR}=$ 0.832, 95\% CI $=0.623-1.112, P=0.215)$.

The heterogeneity of the OS rate in the included datasets was remarkable as determined by the chi-square test and $I^{2}$ statistic $\left(I^{2}=73.8 \%, P_{\mathrm{h}}<0.001\right)$; thus, we employed a random-effects model to measure the HR and 95\% CI. Moreover, subgroup analysis and metaregression examined the possible origin of heterogeneity in our analysis, however, it showed that the heterogeneity was obvious in most stratified analyses, and the heterogeneity was not a result of therapy method $(P=$ $0.805)$, cancer type $(P=0.927)$, analysis method $(P=$ $0.330)$, publication date $(P=0.233)$, sample size $(P=$ $0.247)$, cutoff value $(P=0.897)$ or detected sample $(P=$ $0.176)$.

\section{Correlation between miR-140 levels and CPF of cancer}

In 7 articles, data regarding the relationship between miR-140 levels and the CPF of cancer were reported. A summary of these articles is provided in Table 3 . The pooled OR indicated a marked correlation between miR140 expression and $\mathrm{TNM}$ stage $(\mathrm{OR}=0.420,95 \% \mathrm{CI}=$
$0.299-0.590, P<0.001)$, histologic grade $(\mathrm{OR}=0.410$, 95\% CI $=0.261-0.643, P<0.001)$, and lymph node $(\mathrm{LN})$ metastasis $(\mathrm{OR}=0.341,95 \% \mathrm{CI}=0.144-0.807, P=$ 0.014 ), suggesting that low levels of miR-140 was proportional to advanced TNM stage, worse histologic grade, and positive LN metastasis status. However, miR140 expression was not correlated with age $(\mathrm{OR}=1.068$, 95\% CI $=0.761-1.499, P=0.703)$, sex $(\mathrm{OR}=0.859,95 \%$ $\mathrm{CI}=0.500-1.475, P=0.582)$, or tumor size $(\mathrm{OR}=1.152$, 95\% CI $=0.352-3.773, P=0.815)$.

\section{Sensitivity analysis and publication bias}

To gain insights into the stability of this meta-analysis, further sensitivity analysis was performed. As shown in Fig. 3, each point of the omitted single dataset is estimated to be within the $95 \% \mathrm{CI}$, indicating that the metaanalysis results were not dominated by one single study. Moreover, we used Egger's $(P=0.083)$ and Begg's tests $(P=0.371)$ to assess publication bias in the eligible articles. As shown in Fig. 4, no discernible publication bias was present.

\section{Discussion}

Unhealthy living habits, the intake of toxic substances, and the aging of the population inevitably increases the cancer burden, and marked geographic and economic diversity still exist in cancer prevalence. The mitigation of these factors requires the broad community participation, which reminds us of the recent global assessment of cancer that indicated the need to tailor cancer control mechanisms to local conditions. In fact, the incidence and mortality of cancer have been increasing yearly. Given that the environment cannot be improved in a short time period, researchers have committed to discovering mechanisms underlying the occurrence and development of cancer and finding treatment breakthroughs. Fortunately, in recent years, new advances in the knowledge of genes and proteins and the

Table 3 Meta-analyses of miR-140 expression classified by clinicopathological parameters

\begin{tabular}{|c|c|c|c|c|c|c|c|}
\hline Study covariates & $\begin{array}{l}\text { Studies } \\
\text { (patients) }\end{array}$ & OR $(95 \% \mathrm{Cl})$ & $\begin{array}{l}I^{2} \\
(\%)\end{array}$ & $P_{\mathrm{h}}$ & $\mathbf{Z}$ & $P$ & Model \\
\hline Gender (male/female) & $7(770)$ & $\begin{array}{l}1.068(0.761- \\
1.499)\end{array}$ & 30.0 & 0.199 & 0.38 & 0.703 & Fixed \\
\hline Age $(<60 / \geq 60)$ & $3(257)$ & $\begin{array}{l}0.859(0.500- \\
1.475)\end{array}$ & 0.0 & 0.519 & 0.55 & 0.582 & Fixed \\
\hline Tumor size $(\leq 5 />5 \mathrm{~cm})$ & $3(257)$ & $\begin{array}{l}1.152(0.352- \\
3.773)\end{array}$ & 79.0 & 0.008 & 0.23 & 0.815 & Random \\
\hline TNM stage (1-2/3-4) & $6(614)$ & $\begin{array}{l}0.420(0.299- \\
0.590)\end{array}$ & 43.4 & 0.113 & 5.00 & $\begin{array}{l}< \\
0.001\end{array}$ & Fixed \\
\hline LN metastasis (absence/presence) & $6(568)$ & $\begin{array}{l}0.341(0.144- \\
0.807)\end{array}$ & 78.9 & $\begin{array}{l}< \\
0.001\end{array}$ & 2.45 & 0.014 & Random \\
\hline $\begin{array}{l}\text { Histologic grade (well+ moderately differentiated/ poorly } \\
\text { differentiated) }\end{array}$ & 4 (389) & $\begin{array}{l}0.410(0.261- \\
0.643)\end{array}$ & 0.0 & 0.552 & 3.88 & $\begin{array}{l}< \\
0.001\end{array}$ & Fixed \\
\hline
\end{tabular}

$L N$ lymph node, $O R$ odds ratio, $C l$ confidence intervals, $P_{\mathrm{h}} P$ value for heterogeneity based on $Q$ test, $P P$ value for statistical significance based on $Z$ test 


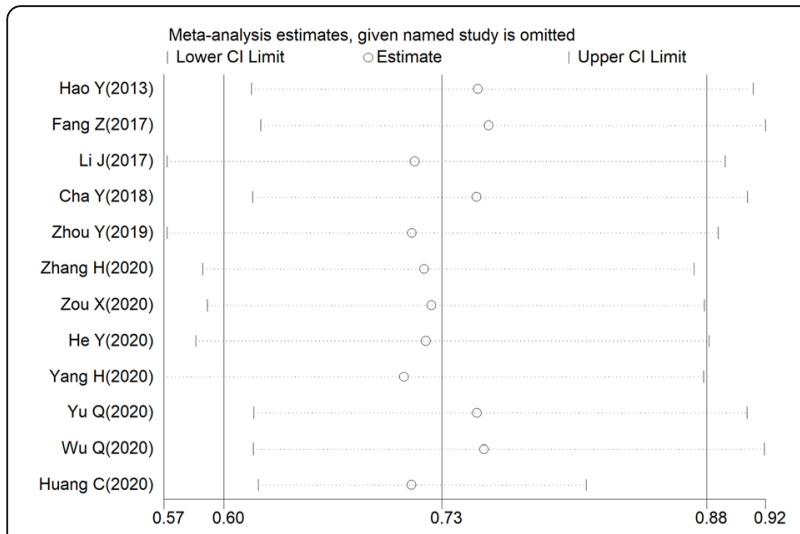

Fig. 3 Sensitivity analysis of overall survival (OS) rates for cancer patients

development of surgical procedures and adjuvant therapies have, to a certain extent, reduced the impact of cancer [30-32]. Based on the current research focus on miRNAs, this we aimed to find a therapeutic direction to further improve the prognosis of tumor patients.

MiRNAs constitute a collection of noncoding RNAs with important impacts on gene expression patterns [6]. As miR-140 is one of the most widely investigated miRNAs, its role in the pathophysiology of neoplastic miRNAs has been comprehensively assessed [33]. However, the role of altered miR-140 levels and function in cancer is still controversial. Recently, diminished expression of miR-140 in cancer tissue has been revealed in numerous cancers. In a previous report, miR-140 was shown to be sponged by circ-ATAD1 during cancer progression. Additionally, its suppression of the epithelialmesenchymal transition was impaired by the oncogenic long noncoding RNA, namely, TMPO-AS1 [34, 35]. In addition, overexpression of miR-140-5p could inhibit proliferation, migration, and invasion and promote apoptosis in cancer by downregulating MAPK1,

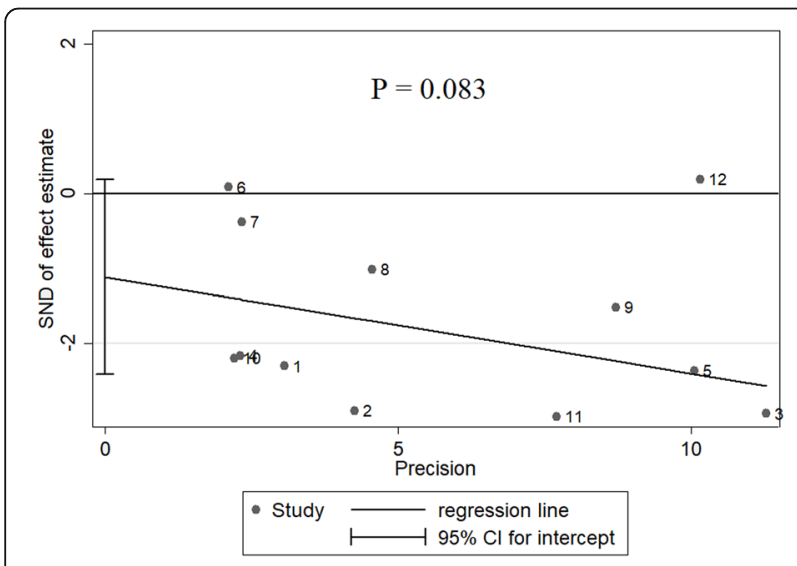

Fig. 4 Effect estimate of publication bias of selected articles, using the Egger's test
TRIM28, and YES1, further regulating levels of cleaved caspase-3, Bcl-2, and Bax, and blocking nuclear transport and $\mathrm{Wnt} / \beta$-catenin signaling $[19,20,25,36,37]$. Emerging studies also showed that low miR-140 levels is closely related to elevated MALAT1 and PAK1 levels [38]. Functionally, miR-140 not only targets oncogene loci but could also be involved in the TLR4/NF- $\mathrm{KB}$ axis and KCNQ1OT1/miR-140-5p/SOX4 axis [39, 40]. Although miR-140 is widely recognized as a tumor suppressor, the suggestion that miR-140 is an oncogenic agent continues to emerge. For instance, miR-140 is highly expressed in certain cancers and promotes cell proliferation, migration, and invasion via its regulation of autophagy and KLF9 levels [29]. Increased expression of miR-140 could modulate cancer cell chemoresistance by targeting IGFBP- 5 and sensitizes osteosarcoma cells to chemotherapy by promoting HMGN5-mediated autophagy $[14,15]$. In addition, the results of clinical utility studies on miR-140 were also varied [18, 22, 29]. Based on these findings, we specifically performed this metaanalysis to examine the prognostic ability of miR-140 levels in cancer.

Here, we selected 12 articles involving 1386 patients. Our data demonstrated that low miR-140 levels are strongly correlated with worse OS in cancer patients. Specifically, the prognostic capability of miR-140 levels was further verified in patients with digestive system cancer, digestive tract cancer, and head and neck cancer. Moreover, this finding was observed in patients with both surgically and nonsurgically treated cancer. Interestingly, it can be seen from the stratified analysis that a majority of the analyses confirmed the prognostic capability of miR-140. Hence, miR-140 expression may be a stand-alone biomarker for cancer patient prognosis. We found significant OS rate heterogeneity among the included studies; however, factors such as therapy method, cancer type, analytic design, publication date, sample population, threshold, and detected sample were not the source of this heterogeneity. Therefore, to eliminate the influence of heterogeneity to some extent, we used a random-effects model to compute the $\mathrm{HR}$ and $95 \% \mathrm{CI}$ where necessary. On the other hand, the results of this meta-analysis indicated that low miR-140 levels were correlated with advanced TNM stage and worse histologic grade and positive LN metastasis in cancer patients. Compared with patients with augmented miR-140 levels, reduced miR-140 levels were strongly associated with advanced tumor grade. Herein, we hypothesize that a low level of miR-140 expression induces tumor progression via several pathways, thus contributing to poor cancer patient prognosis. This is a novel meta-analysis on the clinicopathology and prognosis of miR-140 expression, and our findings can be used to guide subsequent studies related to miR-140 expression. 
Even though our analysis demonstrated valid evidence of the excellent prognostic capacity of miR-140 expression, the limitations associated with this study cannot be ignored. First, 9 different tumor types were analyzed, but only 12 studies were included. Given the low number of studies, the analysis may be unconvincing. Second, different cutoff values of miR-140 expression across studies may have influenced the results. Third, all of the articles were from China, which limits the applicability of the results to other populations. Fourth, some HRs and CIs were computed from survival curves, which inevitably introduced statistical errors. Finally, the level of heterogeneity among the studies was relatively significant and, unfortunately, we did not find the source. Thus, to draw a more convincing conclusion on the clinical utility of miR-140 in cancer patients, additional investigations, involving multiple cancer types, with numerous patients and appropriate and unified methods, are needed worldwide.

\section{Conclusion}

In summary, our meta-analysis, which synthesized the results of all eligible studies, showed that low expression of miR-140 led to worse OS, advanced TNM stage, worse histologic grade, and positive LN metastasis status in cancer patients. Therefore, we have reason to believe that miR-140 is not only a stand-alone indicator of patient survival but may also become a new target for cancer therapy.

\section{Abbreviations}

MiR-140: MicroRNA-140; ORs: Odds ratios; HRs: Hazard ratios; Cls: Confidence intervals; OS: Overall survival; CPF: Clinicopathological features; NOS: Newcastle-Ottawa Quality Assessment Scale; LN: Lymph node

\section{Acknowledgements}

Not applicable.

\section{Authors' contributions}

Study conception and design: M Z and J L. Material preparation, data retrieval, and analysis: J L, C M and K T. Interpretation of the results: $M Z$ and $J$ L. Paper writing: M Z and J L. All authors read and approved the final manuscript.

\section{Funding}

The study was not funded by any resource.

Availability of data and materials

All data are available from the corresponding author.

\section{Declarations}

Ethics approval and consent to participate

Not applicable.

\section{Consent for publication}

Not applicable.

\section{Competing interests}

The authors declare no competing interests.

\section{Author details}

Department of General Surgery, Affiliated Zhejiang Hospital, Zhejiang University School of Medicine, 12 Lingyin Road, Zhejiang 310013, Hangzhou, China. ${ }^{2}$ Department of Health Management, Sir Run Run Shaw International Medical Centre, 9 Jingtan Road, Zhejiang 310000, Hangzhou, China.

Received: 4 June 2021 Accepted: 26 August 2021

Published online: 03 September 2021

\section{References}

1. Bray F, Ferlay J, Soerjomataram I, Siegel RL, Torre LA, Jemal A. Global cancer statistics 2018: GLOBOCAN estimates of incidence and mortality worldwide for 36 cancers in 185 countries. CA Cancer J Clin. 2018;68(6):394-424. https://doi.org/10.3322/caac.21492.

2. Siegel RL, Miller KD, Jemal A. Cancer statistics, 2020. CA Cancer J Clin. 2020; 70(1):7-30. https://doi.org/10.3322/caac.21590.

3. Shi HB, Yu JX, Yu JX, Feng Z, Zhang C, Li GY, et al. Diagnostic significance of microRNAs as novel biomarkers for bladder cancer: a meta-analysis of ten articles. World J Surg Oncol. 2017;15(1):147. https://doi.org/10.1186/s12957017-1201-9.

4. Li P, Li Y, Ma L. Potential role of chimeric genes in pathway-related gene co-expression modules. World J Surg Oncol. 2021;19(1):149. https://doi.org/1 0.1186/s12957-021-02248-9.

5. Cao F, Hu Y, Chen Z, Han W, Lu W, Xu J, et al. Circulating long noncoding RNAs as potential biomarkers for stomach cancer: a systematic review and meta-analysis. World J Surg Oncol. 2021;19(1):89. https://doi.org/10.1186/s12 957-021-02194-6.

6. Bartel DP. MicroRNAs: genomics, biogenesis, mechanism, and function. Cell, 2004;116(2):281-97. https://doi.org/10.1016/s0092-8674(04)00045-5.

7. Friedman RC, Farh KK, Burge CB, Bartel DP. Most mammalian mRNAs are conserved targets of microRNAs. Genome Res. 2009;19(1):92-105. https:// doi.org/10.1101/gr.082701.108.

8. Mendell JT. MicroRNAs: critical regulators of development, cellular physiology and malignancy. Cell Cycle. 2005;4(9):1179-84. https://doi.org/1 0.4161/cc.4.9.2032

9. Yang J, Qin S, Yi C, Ma G, Zhu H, Zhou W, et al. MiR-140 is co-expressed with Wwp2-C transcript and activated by Sox9 to target Sp1 in maintaining the chondrocyte proliferation. FEBS Lett. 2011;585(19):2992-7. https://doi. org/10.1016/j.febslet.2011.08.013.

10. Liu Z, He F, OuYang S, Li Y, Ma F, Chang H, et al. miR-140-5p could suppress tumor proliferation and progression by targeting TGFBRI/SMAD2/3 and IGF1R/AKT signaling pathways in Wilms' tumor. BMC Cancer. 2019;19(1):405. https://doi.org/10.1186/s12885-019-5609-1.

11. Zhai H, Fesler A, Ba Y, Wu S, Ju J. Inhibition of colorectal cancer stem cell survival and invasive potential by hsa-miR-140-5p mediated suppression of Smad2 and autophagy. Oncotarget. 2015;6(23):19735-46. https://doi.org/1 0.18632 /oncotarget.3771

12. Takata A, Otsuka M, Yoshikawa T, Kishikawa T, Hikiba Y, Obi S, et al. MicroRNA-140 acts as a liver tumor suppressor by controlling NF-KB activity by directly targeting DNA methyltransferase 1 (Dnmt1) expression. Hepatology. 2013;57(1):162-70. https://doi.org/10.1002/hep.26011.

13. Güllü G, Peker I, Haholu A, Eren F, Küçükodaci Z, Güleç B, et al. Clinical significance of miR-140-5p and miR-193b expression in patients with breast cancer and relationship to IGFBP5. Genet Mol Biol. 2015;38(1):21-9. https:// doi.org/10.1590/S1415-475738120140167.

14. Meng Y, Gao R, Ma J, Zhao J, Xu E, Wang C, et al. MicroRNA-140-5p regulates osteosarcoma chemoresistance by targeting HMGN5 and autophagy. Sci Rep. 2017;7(1):416. https://doi.org/10.1038/s41598-017-004 05-3.

15. Ahn BY, Elwi AN, Lee B, Trinh DL, Klimowicz AC, Yau A, et al. Genetic screen identifies insulin-like growth factor binding protein 5 as a modulator of tamoxifen resistance in breast cancer. Cancer Res. 2010;70(8):3013-9. https:// doi.org/10.1158/0008-5472.CAN-09-3108.

16. Tierney JF, Stewart LA, Ghersi D, Burdett S, Sydes MR. Practical methods for incorporating summary time-to-event data into meta-analysis. Trials. 2007; 8(1):1-16. https://doi.org/10.1186/1745-6215-8-16.

17. Stang A. Critical evaluation of the Newcastle-Ottawa scale for the assessment of the quality of nonrandomized studies in meta-analyses. Eur J Epidemiol. 2010;25(9):603-5. https://doi.org/10.1007/s10654-010-9491-z.

18. Yang H, Fang F, Chang R, Yang L. MicroRNA-140-5p suppresses tumor growth and metastasis by targeting transforming growth factor $\beta$ receptor 
1 and fibroblast growth factor 9 in hepatocellular carcinoma. Hepatology. 2013;58(1):205-17. https://doi.org/10.1002/hep.26315.

19. Fang $Z$, Yin $S$, Sun $R$, Zhang $S$, Fu M, Wu Y, et al. miR-140-5p suppresses the proliferation, migration and invasion of gastric cancer by regulating YES1. Mol Cancer. 2017;16(1):139. https://doi.org/10.1186/s12943-017-0708-6.

20. Cha Y, He Y, Ouyang K, Xiong H, Li J, Yuan X. MicroRNA-140-5p suppresses cell proliferation and invasion in gastric cancer by targeting WNT1 in the WNT/ß-catenin signaling pathway. Oncol Lett. 2018;16(5):6369-76. https:// doi.org/10.3892/ol.2018.9480.

21. Li J, Gao J, Tian W, Li Y, Zhang J. Downregulation of serum miR-140-5p predicts poor prognosis of patients with colorectal cancer. Int J Clin Exp Pathol. 2017;10(9):9503-8.

22. Zhang $H$, Zou X, Wu L, Zhang S, Wang T, Liu P, et al. Identification of a 7microRNA signature in plasma as promising biomarker for nasopharyngeal carcinoma detection. Cancer Med. 2020;9(3):1230-41. https://doi.org/10.1 $002 /$ cam4.2676

23. Zou X, Zhu D, Zhang H, Zhang S, Zhou X, He X, et al. MicroRNA expression profiling analysis in serum for nasopharyngeal carcinoma diagnosis. Gene. 2020;727:144243. https://doi.org/10.1016/j.gene.2019.144243.

24. Wu Q, Zhu Z. Overexpression of miR-140-3p could reverse radioresistance of nasopharyngeal carcinoma by targeting XIAP. Res Square. 2020;9:1-17. https://doi.org/10.21203/rs.3.rs-73631/v1 .

25. Zhou Y, Wang B, Wang Y, Chen G, Lian Q, Wang H. miR-140-3p inhibits breast cancer proliferation and migration by directly regulating the expression of tripartite motif 28. Oncol Lett. 2019;17(4):3835-41. https://doi. org/10.3892/ol.2019.10038.

26. He Y, Yang Y, Liao Y, Xu J, Liu L, Li C, et al. miR-140-3p inhibits cutaneous melanoma progression by disrupting AKT/P70S6K and JNK pathways through ABHD2. Mol Ther Oncolytics. 2020;17:83-93. https://doi.org/10.101 6/j.omto.2020.03.009.

27. Yang $\mathrm{H}$, Su H, Hu N, Wang C, Wang L, Giffen C, et al. Integrated analysis of genome-wide miRNAs and targeted gene expression in esophageal squamous cell carcinoma (ESCC) and relation to prognosis. BMC Cancer. 2020;20(1):388. 32375686. https://doi.org/10.1186/s12885-020-06901-6.

28. Yu Q, Sun W, Hua H, Chi Y, Liu X, Dong A, et al. Downregulation of miR-140 is correlated with poor prognosis and progression of thyroid cancer. Endocr Metab Immune Disord Drug Targets. 2020. Epub ahead of print;21(4):74955. https://doi.org/10.2174/1871530320666200724180742

29. Huang C, Li J, Zhang X, Xiong T, Ye J, Yu J, et al. The miR-140-5p/KLF9/ KCNQ1 axis promotes the progression of renal cell carcinoma. FASEB J. 2020;34(8):10623-39. https://doi.org/10.1096/fj.202000088RR.

30. Wang K, Chen M, Wu W. Analysis of microRNA (miRNA) expression profiles reveals 11 key biomarkers associated with non-small cell lung cancer. World J Surg Oncol. 2017;15(1):175. https://doi.org/10.1186/s12957-017-1244-y.

31. Que R, Ding G, Chen J, Cao L. Analysis of serum exosomal microRNAs and clinicopathologic features of patients with pancreatic adenocarcinoma. World J Surg Oncol. 2013;1 1(1):219. https://doi.org/10.1186/1477-7819-11-21 9.

32. Qu Y, Chen Y, Zhang L, Tian L. Construction of prognostic predictor by comprehensive analyzing alternative splicing events for colon adenocarcinoma. World J Surg Oncol. 2020;18(1):236. https://doi.org/10.11 86/s12957-020-02010-7.

33. Ghafouri-Fard S, Bahroudi Z, Shoorei H, Abak A, Ahin M, Taheri M. microRNA-140: a miRNA with diverse roles in human diseases. Biomed Pharmacother. 2021;135:111256. https://doi.org/10.1016/j.biopha.2021.1112 56.

34. Zhang L, Chang X, Zhai T, Yu J, Wang W, Du A, et al. A novel circular RNA, circ-ATAD1, contributes to gastric cancer cell progression by targeting miR140-3p/YY1/PCIF1 signaling axis. Biochem Biophys Res Commun. 2020; 525(4):841-9. https://doi.org/10.1016/j.bbrc.2020.02.100.

35. Sun Y, Han C. Long non-coding RNA TMPO-AS1 promotes cell migration and invasion by sponging miR-140-5p and inducing SOX4-mediated EMT in gastric cancer. Cancer Manag Res. 2020;12:1261-8. https://doi.org/10.2147/ CMAR.S235898.

36. Wang J, Zhu M, Zhou X, Wang T, Xi Y, Jing Z, et al. MiR-140-3p inhibits natural killer cytotoxicity to human ovarian cancer via targeting MAPK1. J Biosci. 2020;45(1):66. https://doi.org/10.1007/s12038-020-00036-3.

37. Zhou W, Wang X, Yin D, Xue L, Ma Z, Wang Z, et al. Effect of miR-140-5p on the regulation of proliferation and apoptosis in NSCLC and its underlying mechanism. Exp Ther Med. 2019;18(2):1350-6. https://doi.org/10.3892/etm.2 019.7701.
38. Zhu M, Zhang C, Chen D, Chen S, Zheng H. IncRNA MALAT1 potentiates the progression of tongue squamous cell carcinoma through regulating miR-140-5p-PAK1 pathway. Onco Targets Ther. 2019;12:1365-77. https://doi. org/10.2147/OTT.S192069.

39. Chen X, Deng T, Huo T, Dong F, Deng J. MiR-140-5p/TLR4 /NF-KB signaling pathway: crucial role in inflammatory response in $16 \mathrm{HBE}$ cells induced by dust fall PM2.5. Ecotoxicol Environ Saf. 2021;208:111414. https://doi.org/10.1 016/j.ecoenv.2020.111414.

40. Sun H, Li Y, Kong H, Dai S, Qian H. Dysregulation of KCNQ1OT1 promotes cholangiocarcinoma progression via miR-140-5p/SOX4 axis. Arch Biochem Biophys. 2018;658:7-15. https://doi.org/10.1016/j.abb.2018.09.019.

\section{Publisher's Note}

Springer Nature remains neutral with regard to jurisdictional claims in published maps and institutional affiliations.
Ready to submit your research? Choose BMC and benefit from:

- fast, convenient online submission

- thorough peer review by experienced researchers in your field

- rapid publication on acceptance

- support for research data, including large and complex data types

- gold Open Access which fosters wider collaboration and increased citations

- maximum visibility for your research: over $100 \mathrm{M}$ website views per year

At BMC, research is always in progress.

Learn more biomedcentral.com/submissions 